\title{
Process Planning Review for Mobile Phone Remanufacturing in Indonesia
}

\author{
Yopi Yusuf Tanoto ${ }^{1}$, Shu-San Gan ${ }^{1}$, Didik Wahjudi ${ }^{1}$, Niko Adrisenna Pontjonoto ${ }^{1}$, and \\ Michael Suryajaya ${ }^{2}$ \\ ${ }^{1}$ Mechanical Engineering Department, Petra Christian University, Jl. Siwalankerto No.121-131, \\ Surabaya 60236, Indonesia \\ ${ }^{2}$ Automotive Engineering Department, Coventry University, Priory St, Coventry CV1 5FB, UK
}

\begin{abstract}
The increased number of mobile phone users has an impact on increasing electronic waste (E-Waste) without being offset by the act of product recovery management. Remanufacturing is one way to overcome this. Remanufacturing is a process to return used products to general aesthetics and operating standards. This paper aims to design a mobile phone remanufacturing process in Indonesia. Indonesia is a developing country where mobile usage is quite high. The mobile phones are chosen because it is one of the biggest e-waste takers of late. Several factories were visited in this study. This research uses a qualitative survey, which is carried out in mobile phone factories and service centers. From this research, a design has been made to remanufacture the process on mobile phones. The manufacturing plant verifies the design to obtain the input of the real constraints which will happen when the remanufacturing process is done. The steps in the process of remanufacturing are human machine interface \& visual inspection, separation, disassembly, cleaning, inspection, sorting, reconditioning, reassembly, and final inspection.
\end{abstract}

Keywords: E-waste, hazard and toxic waste, high-end mobile phone, product recovery

\section{Introduction}

Depleted natural resources, increased carbon emissions, and strict government regulations have raised concerns about how to get rid of end-of-life products and have become stronger over the last few decades [1]. In other words, the government has done many ways to incineration to tackle waste, especially electronic waste. These methods include reuse, recycling, and remanufacturing. Remanufacturing is a process for returning used products to the general aesthetic and standard of operation [2]. Lund in Yanbin Du et al. [3] developed seven criteria. One of the criteria is that remanufacturing is reasonable to be connected to technologically stable items. Mobile phones are electronic products that not included in this category. The mobile phone is a relatively low-value product and short life cycle [4]. When the life cycle of mobile phones has ended, making the mobile phone is one of the biggest contributors to e-waste. The wastes of mobile phones are hazardous and toxic, for instance, $\mathrm{Pb}, \mathrm{Cd}, \mathrm{Hg}, \mathrm{As}, \mathrm{Ni}$, and $\mathrm{Cr}$ [5]. There are numerous studies which support the remanufacturing of electronics product. Guide et al. [6] show that the remanufacturing of the short life-cycle product is not only feasible but also can be 
profitable with a well-managed. However, the increasing amount of waste, electrical and electronic equipment (WEEE) causes remanufacturing mobile phones to be an important issue.

In Indonesia, reported that $65 \times 10^{6}$ people used the mobile phone [7]. Study on consumer behaviour of remanufactured products is very important. Wahjudi et al. [8] describe that product knowledge and purchase attitude are identified to have a positive impact on purchase intention of remanufactured mobile phone [8]. This makes electronic waste from a mobile phone in Indonesia a serious problem from the previous research, Tanoto et al. [9] shows that mobile phones remanufacturing in Indonesia can be implemented from the perspective of technical feasibility [9]. This study aims to design a remanufacturing process for mobile phones. This study can provide a review of the process of remanufacturing the phone to the factory, which has not done the remanufacturing process.

\section{Literature review}

\subsection{Remanufacturing Process}

Remanufacturing is a part of product recovery management which consists of repair, remanufacturing, cannibalization, and recycling. From those options, repairing, refurbishing, and remanufacturing have different recovery rates than remanufacturing with the greatest recovery rate. The main purpose of the repairing process is to return the used product to the "working order" product. The quality of these repaired products is usually lower than the quality of the new products. Meanwhile, the product quality of the remanufacturing process is the same or better than the quality of the new products. However, the repairment requires a portion only to disassemble and reassemble, while the remanufacturing process uses full disassemble to form part and reassemble. In contrast, the main purpose of refurbishing is to bring the used products to a certain quality. Refurbishing uses the disassembly of used products until they become modules. The important modules are inspected and repaired or replaced so that quality the service-life will increase. However, the service-life which remains after the refurbishing process is usually less than the average service-life of the new product. According to Steinhilper [10], there are five steps in remanufacturing. These steps can be seen in Figure 1.

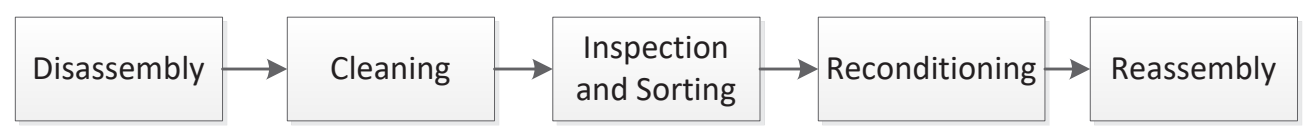

Fig. 1. Five steps of the remanufacturing process.

\subsection{Remanufacturing process on other products}

There are some electronic manufacturers who have already done remanufactured. One of them is Xerox with its copier and printer. Xerox has several production facilities in the world. In Europe, Xerox remanufacturing facilities are in Venray (NL), Mitcheldean (UK), and Dundalk (Ireland). The disassembly process is carried out based on the standard Operator Instruction Cards (OIC), so the process is easy to be tracked and to be audited for quality inspection. Full inspection is done on each existing sub-assembly. Although most components can be reused, some components will be replaced with higher and newer quality to compete with the latest standard. After that, a full test operation will be carried 
out with the same standards and specifications as the new product. Afterward, these remanufactured products will be sent with the same treatment as the new products. The remanufacturing process carried out in Dundalk can be seen in Figure 2 [11].

Caterpillar also processes the remanufacturing of its products [12]. After receiving the core, the first step to do is an inspection. The components which are usually remanufactured are cylinder packs, water pumps, hydraulic components, and other engines' components. Afterward, the component will be dismantled. This process carried out to the nuts and bolts. The part which has been dismantled will be cleaned using an environmentally friendly process. After cleaning, an inspection will be carried out on the quality using the Caterpillar Remanufacture Criteria. Each part which is repaired in this remanufacturing process has the right specifications to ensure that this remanufactured product has the same quality, reliability, and durability as the new items.

Furthermore, the remanufactured product will be rebuilt from the previously repaired part. Tests are done to ensure that this remanufactured product can run properly. After the series of testing, the remanufactured products will be repainted and is ready for sale.

Delphi Technologies also remanufactured their turbocharger [13]. The first step is to disassemble to the part level. Even though some parts of the disposal can function well, it is believed that it will reduce the performance of the turbocharger if it is reused. The discarded parts which will be sent to recycle and the replacement parts will be done before reassembly. The next is cleaning in this step the dismantled parts will be cleaned using chemicals to ensure that the dismantled parts have the same conditions as the new parts. Then, every existed part is inspected to ensure that the parts meet the specified parameters. If there are parts that do not meet the parameters, they will be discarded from the system and recycled. The parts which meet the specified parameters will be merged with the new parts so that the reassembly process can run. After they are assembled, each turbocharger will undergo several industry standard tests to ensure it will work based on the standards. After each turbocharger passes the specified parameters, the remanufactured turbocharger can be sold.

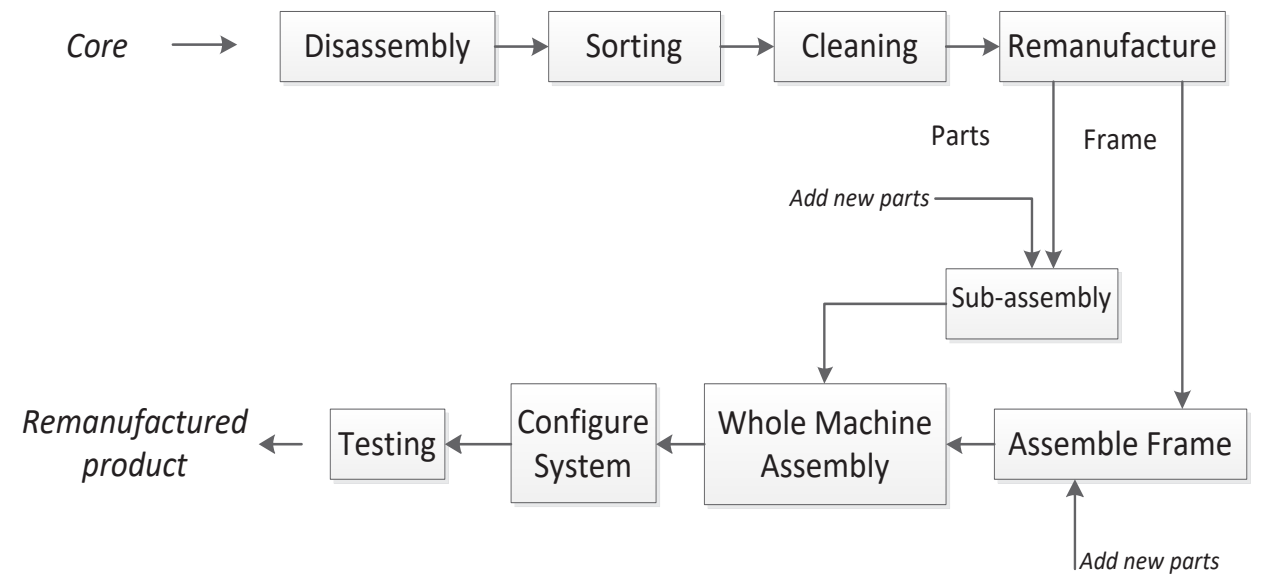

Fig. 2. Xerox remanufacturing process flow chart in Dundalk

\section{Methods}

Conducting interviews and studying the production process of mobile phones at a mobile phone manufacturer in Indonesia is done to obtain the data. This research collected data based on three factories, such as Huawei, Advance, and Polytron. The interview took place in some city in Indonesia from November 2017 until July 2018. 
The interviewees are the owner, plant manager, mechanical design manager and team, and electrical design manager and team. The interview was organized in semi-structured questions, face to face, and recorded. In the other hand, the data also were collected by visiting some services centers to supplement the previous research data [11]. After getting the data, remanufactured mobile process planning can be designed. This process is affiliated with the Steinhilper stage. The process plan will be consulted with expert the factory to minimize the technical problems to enable it to be implemented.

\section{Results and discussions}

\subsection{Results of factory visits}

Through the result of the factory, visits found that no factory produces a whole mobile phone but limited to the assembly process. Among the three factories, there is a factory whose production processes are more intact. The factory does not only assemble but also performs mechanical and electrical design process. This research call the brand " $\mathrm{A}$ " for the secrecy. According to the interview result, there are two types of mobile phones, which are considered suitable for remanufacturing process, high-end and featured phone. High-end mobile phones are possible to be remanufactured because the specifications are almost the same as the new mobile phones. This is because the consumers still demand the specifications. The featured phone is suitable to be remanufactured, especially when there is a specification upgrade process on the mobile phone. Upgrading (specification) process of mobile phones is difficult because the design of the mobile phone must be prepared since the beginning. Human Machine Interface becomes the most favourite upgrade because the consumers can perceive directly.

Reworking mobile phones are not the same as reworking heavy equipment or other products. In infeasible components are replaced to rework the mobile phone. Even though the Printed Circuit Board + Assembly (PCBA) can be reworked, it can only replace the damaged connectors. So, it includes the replacement as well. Planning the remanufacturing process will only be carried out to the modular level instead of the part level. It is because many electronic components are supplied to the mobile manufacturer in the form of modules, such as cameras, LCDs, and more. Most of the modules are supplied from overseas manufacturers. The domestic industry has not been able to produce it. In addition, the costs will be enormous to dismantle and to repair it. For example, the process and the equipment to disassemble LCD Module (LCM) are not easy, so it will be very expensive to fix.

\subsection{Step of mobile phones remanufacturing}

The stages of the remanufacturing process design can be seen in Figure 3. 


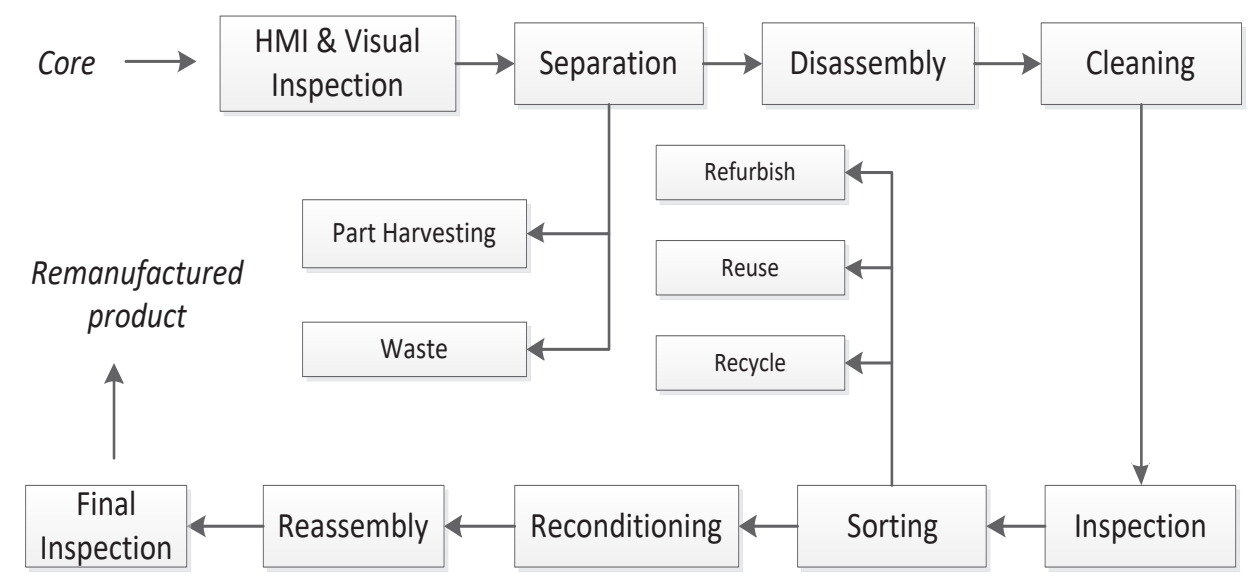

Fig. 3. Steps of mobile phone remanufacturing process.

\subsubsection{Human machine interface (HMI) \& visual inspection}

Checking mobile phones' HMIs and physical conditions are carried out on this stage. HMI can be checked manually or using engineering mode. Engineering mode is a built-in software from the manufacturer which can be used to determine the condition or the performance of the features in the mobile phone. Meanwhile, the physical condition of the mobile phone is checked whether there is damage in the form of scratches, dent, or chipped paint.

\subsubsection{Separation}

The separation will be classified into three options. There are remanufacture (go to next step), part harvesting, and waste. This classification is based on several factors, such as the visual (physical) condition, the cost of the repairment, the complexity of the improvements, the availability of the components, and the time.

\subsubsection{Disassembly}

The next step is to disassemble the mobile phone. Disassembly requires several tools such as tweezers, solder, screwdrivers, picks, headers, and blowers. The sequence of disassembly processes on mobile phones is casing, middle cover, PCBA, peripheral components, and batteries. There are several types of connections which are used in the mobile phone casing, like a snap fit, adhesive, and bolt connection. The snap-fit connection can be removed by hand. After there is a space, the pick can enter and open all existing connections. A blower can open the adhesive connection. The heat will weaken the adhesive on the casing. Then, a cop or pick is used to open the case. Meanwhile, a screwdriver can unscrew the bolt connection.

The next step is removing the middle frame from the mobile phone. There are mobile phones which use the middle frame and do not use the middle frame. The middle frame can be removed by unbolting the bolts. Meanwhile, for the non-middle frame mobile phone, the battery is directly attached to the front cover. PCBA is a major component of mobile phones. In general, there are two types of PCBA. There are PCBCA which unites with the 
sub-board and PCBA which separates from the sub-board. The mobile phone which has separate PCBA sub-board relates to a flat cable called FPC. FPC cable is very easy to break, so the process of disassembly must be done carefully. The process of removing PCBA, which unites with the sub-board uses heating equipment (heater / hot plate). The heat will remove the adhesive material from the PCBA. However, there are also PCBAs which can be revoked.

The next process is to remove the peripheral components from a mobile phone. The peripheral components are the supporting components of the mobile phone, for example, the camera, speaker, antenna, vibrator, and so on. There are two types of connection which are used for the peripheral components. There is a connection which uses solder and connection which uses socket. The process of removing the connection using solder uses solder. Meanwhile, the process of removing the connection using socket only needs to remove it from the socket. The last step is to remove the battery. There are two types of batteries, no-removable battery, and removable battery. While the removable battery is easy to release, the non-removable battery is much more complicated. It is because the adhesive layer must be removed from the battery. A heater can remove the adhesive layer on the battery. However, temperature limit must be heeded since it can cause an explosion. Certain types of mobile phones use strip adhesive on non-removable batteries.

\subsubsection{Cleaning}

After disassembling process, it needs to be cleaned up. However, there are some parts of the mobile phone which need extra care, like the camera, because it can cause damage. This step will carry out the remnants of glue which attached on the parts of the mobile phone. The sticking dust on the components of the old mobile phone is cleaned using a brush. The component which ever exposed to the water can also be found through this step. If the component ever exposed to the water, it will be cleaned using thinner or $90 \%$ alcohol. If fungus is found, it can be cleaned using a Special Thinner or an ultrasonic cleaner. The exposed part is placed in a container soaked by thinner. Then the container will be inserted in an ultrasonic cleaner and turned on for a certain time.

\subsubsection{Inspection}

This step aims to check the components of the mobile phone. There are three types of testing to be carried out, namely, reliability inspection, performance inspection, and safety inspection. The reliability test includes various tests covering the reliability of the mobile phone. However, not all reliability test can be applied to the remanufacturing process of mobile phones. This is because some tests consider destructive. Performance inspection includes features which are owned by mobile phones. This performance aims to ensure that every component of the mobile phone can function properly. Safety inspection covers the level of security on mobile phones when the users use it. For the remanufacturing process, the safety test that can be done is minimal because most of the safety tests are destructive.

\subsubsection{Sorting}

This step aims to classify mobile phones into several groups. There are mobile phones which are recommended for remanufacturing and are not recommended for reconditioning. Mobile phones which are not recommended for the remanufacturing process will be classified based on the recycling processes, which are refurbished, recycle, and reuse. 


\subsubsection{Reconditioning}

Every damaged component will be replaced immediately at this stage. The replacement of the components which are considered 'must-be-replaced' according to the inspection process has been carried out.

\subsubsection{Reassembly}

After replacing the parts reused and unused parts, the next process to do is reassembly. This step aims to rebuild the mobile phone, which has been disassembled. This reassembly process is almost the same as the process of disassembly, but it is done in reverses direction

\subsubsection{Final Inspection}

The last step is to ensure the function of the mobile phone features, whether it works well or not. The feature examination includes signal, Wi-Fi, Bluetooth, microphone, speaker, receiver, front camera, rear camera, autofocus camera, video, camera flash, battery charging, LCD backlight, proximity, USB, home key, volume key, screen lock key, and vibration.

\section{Conclusions}

This study aims to produce a design for the process of remanufacturing on mobile phones. The step of the remanufacturing process of mobile phones which have been made is HMI \& visual inspection, separating, disassembly, cleaning, inspection, sorting, reconditioning, reassembly, and final inspection. This step is useful to provide insight for those who want to remanufacture so that those who want to do remanufacturing can know the steps that must exist in the process of remanufacturing mobile phones. This step is also useful to give an overview to consumers who want to buy a mobile phone for remanufacturing products because some consumers do not believe in this remote processing process. So that with these steps, consumers can find out the procedures performed when the mobile phone remanufacturing process takes place.

\section{References}

1. M.A. Ilgin, S.M. Gupta. J. Environ. Manage., 91,3:563-591(2010). https://www.sciencedirect.com/science/article/pii/S0301479709003417

2. G.C. Souza. Production and Inventory Management Journal. 1,45:56-65(2009). https://search.proquest.com/openview/c38fb4a7c89b260f855ae6e8ea6db8dc/1?cbl=369 $11 \&$ pq-origsite $=$ gscholar

3. Y. Du, H. Cao, F. Liu, C. Li, X, hen. J. Clean. Prod., 20:82-91(2012). https://www.researchgate.net/publication/271882975_An_integrated_method_for_evalu ating the remanufacturability of used machine tool

4. C. Franke, B. Basdere, M. Ciupek, S. Seliger. Omega, 34,6:562-570(2006). https://www.sciencedirect.com/science/article/pii/S0305048305000241

5. J. Yu, E. Williams, M. Ju. Energy Policy, 38,8:4135-4141(2010). https://www.sciencedirect.com/science/article/pii/S0301421510002041

6. V.D.R. Guide Jr., R.H. Teunter, L.N.V. Wassenhove. Manufacturing \& Service Operations Management, 5,4:303-316(2003).

https://pubsonline.informs.org/doi/abs/10.1287/msom.5.4.303.24883 
7. Ristekdikti Press Conference, Smartphone rakyat Indonesia, No. 02/SP/HM/BKKP/I/2017 [Online] from: https://ristekdikti.go.id/siaranpers/smartphone-rakyat-indonesia-2/ (2017) [Accesed on 3 July 2017].

8. D. Wahjudi, S.S. Gan, J. Anggono, Y.Y. Tanoto. Int. J. Bus. Soc., 19,2:415-428(2018). https://www.researchgate.net/publication/327222133_Factors_Affecting_Purchase Inte ntion of Remanufactured Short Life-Cycle Products

9. Y.Y. Tanoto, S.S. Gan, D. Wahjudi, J. Anggono. JTEC, 10,2-3:117-121(2018.). http://journal.utem.edu.my/index.php/jtec/article/view/4203

10. R. Steinhilper. Remanufacturing: The ultimate form of recycling. Stuttgart: Fraunhofer IRB Verlag (1998). p. 7-40. https://docplayer.net/57735396-Rolf-steinhilperremanufacturing-the-ultimate-form-of-recycling-fraunhofer-irb-verlag.html

11. A. King, S. Barker, A. Cosgrove. Remanufacturing at Xerox: Evaluating the process to establish principles for better design. Paper presented at the International Conference On Engineering Design (Paris, France, 2007). p. 1-11 https://www.designsociety.org/download-

publication/25699/Remanufacturing + at + Xerox $\% 3 \mathrm{~A}+$ Evaluating + the + Process + to + Estab $\underline{\text { lish+Principles+for+Better+Design }}$

12. MIT. Caterpillar remanufacturing Singapore overview [Online] from http://web.mit.edu/sma/events/career fair/2008/cat_overview.pdf (2008). [Accessed on 17 July 2018].

13. Delphiautoparts. Remanufacturing: What is the process? [Online] from: https://www.delphiautoparts.com/bra/en/toolbox/remanufacturing-what-process (2018). [Accessed on 17 July 2018]. 